
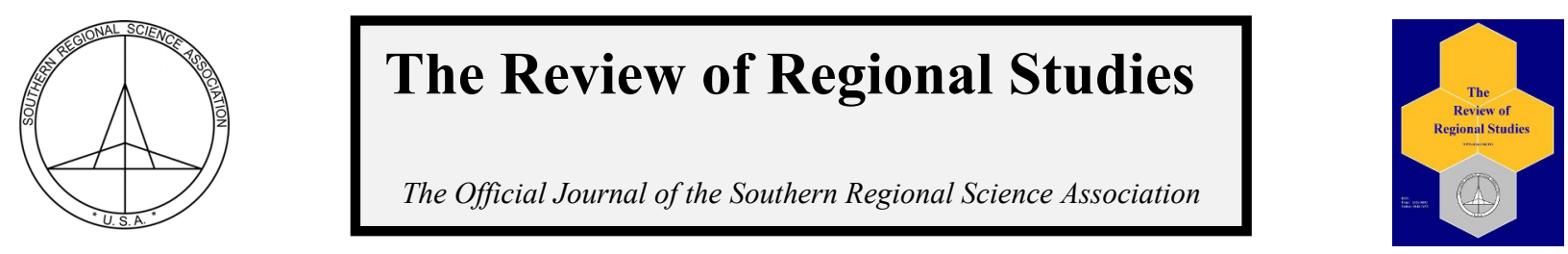

\title{
Gender, Occupational Segregation, and the Cultural Divide: Are Red States Different than Blue States?*
}

\author{
Ann Mari May and Mary G. McGarvey \\ Department of Economics, University of Nebraska-Lincoln, USA
}

\begin{abstract}
This paper examines geographic differences in occupational segregation by sex in male-dominated, higheducation STEM and non-STEM occupations to determine if labor market conditions for women vary according to red-state/blue-state patterns. Controlling for state demographic variables, economic factors, and labor market characteristics, our results show that there are indeed differences in labor market outcomes along red-state/blue-state lines, with blue states showing more integrated labor market outcomes than red states. Our results suggest that there may indeed be important differences in labor market outcomes for women associated with values differences in red versus blue states.
\end{abstract}

Keywords: occupational segregation, spatial variation

JEL Codes: R23, J16, Z10

\section{INTRODUCTION}

In 2004, a little-known state legislator from Illinois, Barack Obama, gave the keynote address at the Democratic National Convention, declaring, "There is not a liberal America and a conservative America - there is a United States of America." The pundits, he went on to say "like to slice-and-dice our country into Red States and Blue States: Red States for Republicans, Blue States for Democrats. But I've got news for them, too...We are one people, all of us pledging allegiance to the stars and stripes, all of us defending the United States of America."

The rhetoric of red states and blue states continues to frame our thinking about the political landscape of contemporary society. First introduced by James Davison Hunter (1991) in his Culture Wars: The Struggle to Define America, the notion of deep divisions on moral issues such as abortion, women's rights, gay marriage, and stem cell research, struck a chord with journalists and with average Americans. When Hunter introduced the idea of a culture war in 1991, he surely could not have appreciated the degree to which this notion would resonate and continue to serve as shorthand for seemingly significant divisions in society.

\footnotetext{
* The authors wish to thank Kacey Douglas for her research assistance and the editors and referees for their valuable comments and suggestions.

Ann Mari May is Professor of Economics at the University of Nebraska-Lincoln, Lincoln, NE 68516. Mary G. McGarvey is Associate Professor of Economics at the University of Nebraska-Lincoln, Lincoln, NE 68516. Corresponding Author: A.M. May E-mail: amay1@unl.edu.

${ }^{1}$ Keynote speech by Barack Obama, 2004 Democratic National Convention, http://www.americanrhetoric.com/speeches/convention2004/barackobama2004dnc.htm, accessed August 9, 2016.
}

(C) Southern Regional Science Association 2017. 
At the same time that political pundits and social scientists alike have examined election returns and opinion polls searching for evidence of the so-called new culture wars, demographers have identified trends in household formation that they claim represent significant changes from previous long terms trends. While the first demographic transition was characterized by declining mortality rates, falling birth rates, zero population growth, longer life expectancy, and households converging toward nuclear types of married couples with children, Lesthaeghe (2010) and others now claim that a second demographic transition is underway. According to this view, the second demographic transition, which occurred in European countries first and is now increasingly evident in the U.S. in certain regions, is characterized by subreplacement fertility, a multitude of living arrangements other than marriage, the disconnection between marriage and procreation, and the converging of the economic lives of men and women (Lesthaeghe and Surkyn, 1988; Lesthaeghe, 2010). According to Lesthaeghe and Neidert (2006), the values typically associated with the second demographic transition include secularization, emergence of a new political left, individual autonomy with respect to ethics, tolerance for unconventional or relativist ethics and an enhanced preoccupation with individuality and selfactualization, and egalitarianism with "an emphasis on gender equity, tolerance for all minorities including sexual ones..." (Lesthaeghe and Neidert, 2006, p. 4).

Not surprisingly perhaps, Lesthaeghe and Neidert (2007) have begun to examine the political significance of the second demographic transition, arguing that there is a statistical link between voting outcomes in the U.S. in presidential elections and measurable demographic trends in marriage, cohabitation, abortion, and family formation associated with the second demographic transition. Not only do significant numbers of Americans hold different views, they also display different behaviors.

While there is little consensus as of yet on the ideological underpinnings of the culture wars, ${ }^{2}$ at least some political scientists have noted the centrality of women at the core of the issues in these debates. As Brewer and Stonecash (2007, p. 13) have pointed out, "The place of women in American society is a rallying point in the cultural debates and almost all of those on the conservative side of the cultural divide place the health of the American family as perhaps the biggest umbrella concern of all." Moreover, the centrality of women in the culture wars may indeed reflect the structural changes reflected in the second demographic transition-changes in fertility, marriage, and women's labor force participation brought about by increases in women's education and changes in technology (Lesthaeghe, 2010; Goldin, 2006).

While attention has been paid to voting outcomes as they relate to the second demographic transition, little attention has been paid to the impact of this transition on women's labor market outcomes. That is, if the advent of the second demographic transition is advancing in an uneven pattern in the U.S. as reflected in red-state/blue-state comparisons, do we see variations in labor market outcomes for women that reflect these differences in values? More specifically, if the second demographic transition reflects variations in social preferences on gender equity along with geographic differences in the convergence of the economic lives of men and women, should we not expect to see women more fully integrated into the labor market in high-education, male-dominated fields in blue states versus red states?

\footnotetext{
${ }^{2}$ For an alternative view of the culture wars see Fiorina, Abrams, and Pope (2006, p. 8), who argue that Americans are centrist in their beliefs and have more shared values than differences. In their words, "The simple truth is that there is no culture war in the United States - no battle for the soul of America rages, at least none that most Americans are aware of."
}

(C) Southern Regional Science Association 2017. 
To consider this question, we use a measure of occupational segregation similar to the location quotient that the U.S. Bureau of Labor Statistics (BLS) applies to compare the concentration of industry specific employment across states. Here the location quotient is applied to compare gender employment ratios across states in male-dominated/high-education occupations to determine if labor market outcomes for women vary according to red-state/bluestate patterns. We examine occupations in which educational attainment "levels the playing field," although women may yet encounter cultural barriers that prevent them from fully participating in these male-dominated occupations or be reluctant to apply for male-dominated jobs due to cultural norms. This research allows us to understand an important, yet little-known aspect of the impact of the values divide in red states and blue states - the impact of this cultural divide on women's labor market outcomes. ${ }^{3}$

\section{MEASURING OCCUPATIONAL SEGREGATION}

One of the most remarkable changes in the labor market over the last third of the $20^{\text {th }}$ century has been the large increase in the number of female workers. Labor force participation rates for women aged 16 years and older nearly doubled, rising from 33.9 percent in 1950 to 58.6 percent in 2010 (Fullerton, 1999). Whereas women constituted only one in five workers in 1900, today nearly half of all workers in the U.S. are now women.

Long-term trends in occupational segregation showed little change in the first six decades of the $20^{\text {th }}$ century. However, occupational segregation by gender began to decline slightly beginning in 1960s (Blau and Hendricks, 1979) and accelerated greatly during the 1970s (Bianchi and Rytina 1986). As several other studies such as Jacobsen (1994, 1997), Bertaux (1991), Jacobs (1989), Albelda (1986), and Goldin (1990) have shown, occupational segregation by sex, which had remained roughly unchanged throughout much of the $20^{\text {th }}$ century and began to markedly decline in the 1970s and 1980s, began leveling off somewhat in the $1990 \mathrm{~s} .{ }^{4}$ In terms of the labor market in the U.S., it appears that initial reductions in occupational segregation have roughly coincided with the onset of the second demographic transition.

Most studies of occupational segregation employ the dissimilarity index (DI) to measure the degree of occupational segregation of men and women among multiple occupations (Duncan and Duncan, 1955). The DI is a useful measure of occupational segregation that tells us in one measurement how many men and women would have to change occupations for there to be equal proportions of women and men in each occupational category. ${ }^{5}$

While the DI reveals much about the degree of segregation of men and women in the labor market, because of the aggregative nature of the measure it does not reveal much about the underlying nature of that segregated labor market. That is, we may see a reduction in the DI over time but have little knowledge about why the reduction has occurred. Such a reduction might be the result of women becoming increasingly employed in male-dominated occupations, or by men becoming increasingly employed in female occupations, or by a growth in integrated occupations.

\footnotetext{
${ }^{3}$ Guiso, Sapienza, and Zingales (2006) provide a provocative and interesting discussion examining whether culture affects economic outcomes and call for rigorous testing of such cases where culture does indeed appear to influence economic outcomes.

${ }^{4}$ Although women continue to enter male-dominated occupations, evidence by King (1992) suggests that the breakdown of occupational segregation slowed somewhat in the 1980s.

${ }^{5}$ When trends are the focus, the index of dissimilarity is often supplemented with a size-standardized index of dissimilarity, which allows us to hold the relative size of occupations constant.
}

(C) Southern Regional Science Association 2017. 
Although early studies of occupational segregation emphasized human capital explanations (Mincer and Polachek, 1974) for women's labor market "choices," subsequent studies emphasize the role of employer choices. ${ }^{6}$ Bergmann (1974), Blumberg (1979), and Strober (1984), for example, argued early on that women face barriers to entry into certain occupations. As a result, much of the empirical research has focused on whether occupational segregation is a result of discrimination on the part of employers or male employees or the result of women's own choices (Beller, 1982; Blau, 1984).

Given the growing participation of women in the labor market and rising education rates for women, structural labor market and demographic characteristics are increasingly important for explaining differences in occupational segregation. These structural factors include the size of the business enterprise, unemployment, unionization, and demographic characteristics such as median age of the population, population density, and rurality (Abrahamson and Sigelman, 1987; Albelda, 1986; Beller, 1985; Lorence, 1992; Olfert and Moebis, 2006).

Often missing from this literature is formal treatment of the spatial dimensions of labor markets. Either implicitly or explicitly, the assumptions of perfectly competitive, profitmaximizing firms and of inputs with perfect mobility and perfect information have served to obfuscate variations in occupational segregation by city or region (Brunell, 1997). Studies such as Lorence (1992) examine spatial dimensions of occupational segregation by including region (Northeast, North Central, West, and South within the U.S.) as explanatory variables, but examining a finer spatial grain should better identify regional differences in gender attitudes and, hence, variations in occupational segregation that result from these differences.

Perhaps because of the use of the DI in measuring occupational segregation in labor markets, few studies have examined the dynamics of the process whereby individuals and firms have responded to the entry of women into the labor force and geographic variations in labor market outcomes for women. One important exception is Pan (2015) who provides a more detailed examination of the dynamics of occupational segregation by focusing on tipping points. Tipping points occur when women enter an occupation in sufficient numbers to cause men to leave that occupation. In other words, tipping points result from male preferences in relation to the share of women working in a given occupation. ${ }^{7}$ Using U.S. Census data from 1940 to 1990, Pan (2015) finds that tipping points are lower in regions of the country where men hold more sexist attitudes, and her results suggest an important link between male gender attitudes and occupational segregation. These results, she argues, are consistent with Schelling's (1971) social interaction model on neighborhood tipping.

Another exception is Olfert and Moebis (2006) who examine regional differences in gender-based occupational segregation in Canada using the DI in the year 2000. In this study, factors explaining the variation in occupational segregation by province/territory in Canada, as measured by the DI, include industry characteristics, manufacturing employment, education, children at home, percentage of the labor force that is female, as well as rurality (population density) presented as a fixed effect. Olfert and Moebis (2006) conclude that education, presence of children, and rurality are significant factors explaining variations in occupational segregation by region and that rurality may reflect differences in various costs of commuting, relative

\footnotetext{
${ }^{6}$ See England (1982) for a full critique of human capital theory and occupational segregation.

7 The approach by Pan is consistent with a social interaction model similar to that introduced by Schelling (1971) in his examination of race and neighborhood tipping.
}

(c) Southern Regional Science Association 2017. 
scarcity of choice in employment opportunities, greater difficulty in coordinating employment in two-income earner families, and perhaps more traditional views with respect to employment roles of men and women.

In order to understand the degree to which women are over- or under-represented in particular types of occupations in a state, we use an alternative measure of occupational segregation that we call the gender concentration quotient (GCQ). The GCQ is similar to a location quotient used by economic geographers and regional economists, except that occupational groups rather than industries are the subgroups examined. ${ }^{8}$ This measure is also similar to the location quotient as used by the BLS, except that the BLS measure looks at employment concentrations in general while we instead examine female employment patterns as they compare to male employment patterns. ${ }^{9}$ Specifically, the state GCQ indicates whether a particular occupation employs more (or fewer) women than would be expected given the employment patterns of men statewide. The GCQ has the advantage of providing a continuous measure of the degree to which women are under- or over-represented in a particular occupation allowing us to identify male-dominated, female-dominated, and integrated occupations within the context of variations in labor market participation by sex.

The GCQ is defined as:

$$
\begin{gathered}
G C Q_{i s}=W_{i s} / W_{i s}{ }^{*} \\
W_{i s}{ }^{*}=\left(M_{i s} / T M_{s}\right) \times T W_{s}
\end{gathered}
$$

where $W_{i s}$ is the actual number of women employed in occupation $i$ in state $s$ and $W_{i s}{ }^{*}$ is the expected number of women employed in occupation $i$ in state $s$ if women were employed in occupation $i$ in state $s$ in the same proportion that men are employed in occupation $i$ in state $s$. Thus, $W_{i s}{ }^{*}$ is derived by taking the proportion of men employed in occupation $i$ in state $s$ multiplied by the total number of women employed in state $s\left(T W_{s}\right)$. In other words, $M_{i s}$ is the number of men employed in occupation $i$ in state $s$ and $T M_{s}$ denotes the total number of men employed in the state. The gender concentration quotient can be interpreted in the following manner:

If $G C Q$ is $>1$, then more women are working in state $s$ in occupation $i$ than expected based on male employment patterns in that occupation.

If $G C Q$ is $<1$, then fewer women are working in state $s$ in occupation $i$ than expected based on male employment patterns in that occupation.

By rearranging the terms in the definition of the state's GCQ in occupation $i$, we see that $G C Q_{i s}$ is the proportion of female workers in the state who are working in occupation $i\left(W_{i s} / T W_{s}\right)$ divided by the proportion of male workers in the state who are working in occupation $i$ $\left(M_{i s} / T M_{s}\right)$. The $G C Q_{i s}$ measures the concentration of women relative to men in the state who are working in the $i$ th occupation. Because the $G C Q_{i s}$ accounts for the gender ratio of total employment in state $s$, the measure is ideally suited for across-state comparisons of the degree of state gender segregation within a specific occupation $i$.

\footnotetext{
${ }^{8}$ See Burt and Barber (1996) for a discussion of the use of location quotients.

${ }^{9}$ A BLS web tool allows comparisons of employment in a defined area to that of a larger base. See http://www.bls.gov/cew/cewlq.htm accessed July 1, 2015.
}

(C) Southern Regional Science Association 2017. 
In this study, we use 2000 census data for the continental U.S. to construct statewide gender concentration quotients for each male-dominated occupation (those occupations where less than 50 percent of those employed are women) that employs highly educated workers (occupations in which at least 80 percent of workers hold a college degree). Controlling for a variety of state demographic variables, economic factors, and labor market conditions, we use the GCQ to examine female representation in male-dominated, high-education occupations in red states versus blue states to determine if there are patterns of occupational segregation that might reflect the values differences consistent with the second demographic transition.

In addition, we estimate the GCQ relationships separately for both STEM (science, technology, engineering, and math) and non-STEM occupations. ${ }^{10}$ We do this for several reasons. First, Pan's (2015) results demonstrate that tipping points are lowest in more-skilled occupations where more-highly educated workers are employed. We examine STEM fields separately to see if there are indeed fewer women in these occupations than in other non-STEM, high-education/male-dominated occupations. Second, we separate STEM and non-STEM occupations to account for the expected positive relationship between religious and political conservatism and male occupational preferences for STEM occupations. Grossmann et al. (2015) find that men (but not women) from more religiously and politically conservative backgrounds prefer work in occupations that require college majors in STEM fields and that this preference is reflected in their choice of college major. These findings suggest that the concentration of women (relative to men) employed in STEM occupations versus non-STEM occupations, in both red and blue states, will respond differently to variations in state measures of religious conservatism and state measures of educational attainment of women (relative to men).

In contrast to Pan's (2015) study which examines variations in male preferences against working alongside women in occupations and its impact on tipping points in occupations over time, our analysis examines the potential impact of a broader state culture on, not only worker attitudes, but on employer attitudes. In other words, if the second demographic transition reflects a convergence of the economic lives of men and women and a preference for gender equality (or cultural values that reflect less gender bias), we should expect to see less segregation and more women relative to men in these occupations in blue states than in red states.

\section{OCCUPATIONAL SEGREGATION BY SEX IN RED STATES AND BLUE STATES}

Our goal is to estimate the effect of systematic differences in red states' versus blue states' political and social environments on the concentration of women (relative to men) employed in male-dominated, high-education occupations. Table 1 describes the occupations from the 2000 U.S. decennial census that satisfy our male-dominated, high-education criteria and provides a picture of the degree of female segregation in these occupations during the 2000 Presidential election year. The 56 occupations shown employed the most highly educated workers in eleven major Standard Occupational Classification (SOC) System categories, which include management, business and financial, computer and math, architects and engineers, scientists, community services, legal, education, arts, healthcare, and transportation. At least 80 percent of all workers in the high-education occupations in our study are college graduatessubstantially above the 19 percent figure for workers in all occupations in the year 2000 .

\footnotetext{
${ }^{10}$ STEM occupations are identified by the U.S. Census Bureau and can be found by visiting www.census.gov/people/io/methodology/. For further information see Landivar (2013).
}

(C) Southern Regional Science Association 2017. 
Table 1: Male-dominated Occupations with Highly Educated Workers 2000 U.S. Census Occupational Data for 48 Contiguous States

\begin{tabular}{|c|c|c|c|c|c|c|c|c|c|c|c|}
\hline \multirow[b]{2}{*}{ Census Code } & \multirow[b]{2}{*}{ Occupations within Census Categories } & \multirow{2}{*}{$\begin{array}{c}\text { Percent } \\
\text { Workers } \\
\text { with BA } \\
\end{array}$} & \multirow{2}{*}{$\begin{array}{c}\text { Median } \\
\text { Earnings } \\
(\$ 1000) \\
\end{array}$} & \multicolumn{3}{|c|}{ Mean State GCQ } & \multicolumn{3}{|c|}{$\begin{array}{c}\text { Mean State Proportion of full- } \\
\text { time Workers in Occupation } \\
\text { that are Female }\end{array}$} & \multicolumn{2}{|c|}{$\begin{array}{l}\text { Number of States with } \\
\text { Full-time Employment in } \\
\text { Occupation }\end{array}$} \\
\hline & & & & All & Blue & Red & All & Blue & Red & Blue & Red \\
\hline \multicolumn{12}{|c|}{ Management } \\
\hline 1 & Chief executives & 81.6 & 87.51 & 0.26 & 0.26 & 0.25 & 0.18 & 0.19 & 0.18 & 19 & 29 \\
\hline 3 & Legislators & 85.9 & 50.57 & 0.76 & 0.69 & 0.80 & 0.37 & 0.37 & 0.37 & 19 & 29 \\
\hline 5 & $\begin{array}{l}\text { Marketing and Sales Managers } \\
\text { Computer and Information Systems Managers }\end{array}$ & 81.8 & 57.17 & 0.84 & 0.85 & 0.84 & 0.42 & 0.43 & 0.42 & 19 & 29 \\
\hline 11 & (STEM) & 83.3 & 67.51 & 0.50 & 0.48 & 0.51 & 0.30 & 0.30 & 0.30 & 19 & 29 \\
\hline 30 & Engineering Managers (STEM) & 89.3 & 80.94 & 0.07 & 0.08 & 0.07 & 0.06 & 0.06 & 0.05 & 19 & 29 \\
\hline 36 & Natural Sciences Managers (STEM) & 94.6 & 75.51 & 0.75 & 1.15 & 0.48 & 0.31 & 0.39 & 0.27 & 19 & 29 \\
\hline \multicolumn{12}{|c|}{ Business and Financial } \\
\hline 71 & Management Analysts & 87.5 & 58.34 & 0.73 & 0.74 & 0.73 & 0.39 & 0.40 & 0.39 & 19 & 29 \\
\hline 84 & Financial Analysts & 91.5 & 60.24 & 0.60 & 0.67 & 0.55 & 0.33 & 0.36 & 0.32 & 19 & 28 \\
\hline 85 & Personal Financial Advisors & 88.1 & 56.42 & 0.54 & 0.58 & 0.52 & 0.32 & 0.34 & 0.31 & 19 & 29 \\
\hline 90 & Financial Examiners & 90.7 & 53.20 & 0.87 & 0.96 & 0.81 & 0.40 & 0.44 & 0.37 & 17 & 28 \\
\hline \multicolumn{12}{|c|}{ Computer and Math (all STEM) } \\
\hline 100 & Computer Scientists and System Analysts & 81.2 & 52.86 & 0.58 & 0.59 & 0.58 & 0.34 & 0.34 & 0.33 & 19 & 29 \\
\hline 101 & Computer Programmers & 83.0 & 54.47 & 0.43 & 0.44 & 0.43 & 0.28 & 0.28 & 0.27 & 19 & 29 \\
\hline 102 & Computer Software Engineers & 88.9 & 64.03 & 0.42 & 0.38 & 0.45 & 0.27 & 0.25 & 0.27 & 19 & 29 \\
\hline 106 & Database Administrators & 82.8 & 53.21 & 1.08 & 0.74 & 1.31 & 0.41 & 0.39 & 0.43 & 19 & 29 \\
\hline 120 & Actuaries & 96.8 & 72.45 & 0.70 & 0.88 & 0.56 & 0.34 & 0.37 & 0.31 & 18 & 22 \\
\hline 122 & Operations Research Analysts & 82.0 & 51.87 & 0.97 & 0.97 & 0.97 & 0.45 & 0.46 & 0.44 & 19 & 29 \\
\hline \multicolumn{12}{|c|}{ Architects and Engineers (all STEM) } \\
\hline 130 & Architects, Except Naval & 93.0 & 51.08 & 0.27 & 0.30 & 0.25 & 0.19 & 0.21 & 0.17 & 19 & 29 \\
\hline 132 & Aerospace Engineers & 91.8 & 64.48 & 0.15 & 0.10 & 0.18 & 0.09 & 0.08 & 0.11 & 19 & 29 \\
\hline 135 & Chemical Engineers & 93.8 & 67.18 & 0.17 & 0.19 & 0.16 & 0.13 & 0.15 & 0.12 & 19 & 28 \\
\hline 136 & Civil Engineers & 92.0 & 56.68 & 0.12 & 0.13 & 0.11 & 0.09 & 0.11 & 0.09 & 19 & 29 \\
\hline 140 & Computer Hardware Engineers & 82.4 & 60.05 & 0.29 & 0.25 & 0.31 & 0.19 & 0.17 & 0.19 & 19 & 27 \\
\hline 141 & $\begin{array}{l}\text { Electrical and Electronic Engineers } \\
\text { Industrial Engineers, Including Health and }\end{array}$ & 87.7 & 63.25 & 0.10 & 0.09 & 0.10 & 0.08 & 0.07 & 0.08 & 19 & 29 \\
\hline 143 & Safety & 81.0 & 51.94 & 0.22 & 0.23 & 0.21 & 0.16 & 0.17 & 0.15 & 19 & 29 \\
\hline 144 & Marine Engineers and Naval Architects & 86.5 & 60.31 & 0.09 & 0.10 & 0.08 & 0.06 & 0.07 & 0.06 & 15 & 20 \\
\hline 145 & Materials Engineers & 83.5 & 55.67 & 0.15 & 0.15 & 0.15 & 0.11 & 0.12 & 0.11 & 19 & 28 \\
\hline 146 & Mechanical Engineers & 85.3 & 57.83 & 0.07 & 0.07 & 0.06 & 0.06 & 0.06 & 0.05 & 19 & 29 \\
\hline 151 & Nuclear Engineers & 92.4 & 71.98 & 0.15 & 0.10 & 0.18 & 0.10 & 0.08 & 0.12 & 15 & 22 \\
\hline 152 & Petroleum Engineers & 93.6 & 76.53 & 0.08 & 0.09 & 0.08 & 0.06 & 0.06 & 0.06 & 15 & 28 \\
\hline 153 & $\begin{array}{l}\text { Engineers, All Others } \\
\text { Surveyors, Cartographers, and }\end{array}$ & 88.3 & 61.35 & 0.12 & 0.12 & 0.12 & 0.09 & 0.10 & 0.09 & 19 & 28 \\
\hline 156 & Photogrammetrists & 87.1 & 41.77 & 0.14 & 0.15 & 0.13 & 0.11 & 0.12 & 0.10 & 19 & 29 \\
\hline \multicolumn{12}{|c|}{ Life, Physical and Social Scientists (all STEM) } \\
\hline 160 & Agricultural and Food Scientists & 89.5 & 41.19 & 0.41 & 0.44 & 0.38 & 0.26 & 0.28 & 0.24 & 19 & 29 \\
\hline 161 & Biological Scientists & 96.2 & 41.13 & 0.82 & 0.91 & 0.76 & 0.41 & 0.44 & 0.39 & 19 & 29 \\
\hline 164 & Conservation Scientists and Foresters & 92.6 & 43.70 & 0.34 & 0.53 & 0.23 & 0.18 & 0.21 & 0.16 & 18 & 29 \\
\hline 165 & Medical Scientists & 98.6 & 47.33 & 1.00 & 0.96 & 1.03 & 0.46 & 0.46 & 0.46 & 19 & 27 \\
\hline 170 & Astronomers and Physicists & 96.0 & 69.12 & 0.21 & 0.20 & 0.23 & 0.15 & 0.14 & 0.15 & 19 & 26 \\
\hline 171 & Atmospheric and Space Scientists & 92.8 & 56.10 & 0.18 & 0.21 & 0.17 & 0.13 & 0.15 & 0.12 & 17 & 29 \\
\hline 172 & Chemists and Materials Scientists & 95.2 & 50.47 & 0.51 & 0.57 & 0.47 & 0.30 & 0.33 & 0.29 & 19 & 29 \\
\hline 174 & Environmental Scientists and Geoscientists & 95.6 & 50.47 & 0.37 & 0.41 & 0.34 & 0.24 & 0.27 & 0.22 & 19 & 29 \\
\hline 176 & Physical Scientists, All Other & 97.8 & 50.76 & 0.60 & 0.61 & 0.59 & 0.34 & 0.35 & 0.34 & 19 & 29 \\
\hline 180 & Economists & 99.4 & 70.25 & 0.50 & 0.45 & 0.52 & 0.29 & 0.28 & 0.29 & 19 & 29 \\
\hline 184 & Urban and Regional Planners & 95.8 & 50.31 & 0.54 & 0.54 & 0.53 & 0.31 & 0.31 & 0.30 & 19 & 28 \\
\hline \multicolumn{12}{|c|}{ Community, Social Services } \\
\hline 204 & Clergy & 88.7 & 31.29 & 0.20 & 0.25 & 0.17 & 0.15 & 0.18 & 0.13 & 19 & 29 \\
\hline \multicolumn{12}{|c|}{ Legal } \\
\hline 210 & $\begin{array}{l}\text { Lawyers } \\
\text { Judges, Magistrates, and Other Judicial }\end{array}$ & 99.4 & 82.14 & 0.41 & 0.45 & 0.39 & 0.27 & 0.28 & 0.25 & 19 & 29 \\
\hline 211 & Workers & 91.3 & 71.42 & 0.67 & 0.71 & 0.65 & 0.36 & 0.38 & 0.35 & 19 & 29 \\
\hline & Education & & & & & & & & & & \\
\hline 220 & Postsecondary Teachers & 95.4 & 46.70 & 0.97 & 1.00 & 0.96 & 0.46 & 0.47 & 0.45 & 19 & 29 \\
\hline & Arts & & & & & & & & & & \\
\hline 271 & $\begin{array}{l}\text { Producers and Directors } \\
\text { Athletes, Coaches, Umpires, and Related }\end{array}$ & 85.5 & 44.02 & 0.64 & 0.69 & 0.61 & 0.36 & 0.38 & 0.34 & 19 & 29 \\
\hline 272 & Workers & 80.6 & 33.24 & 0.57 & 0.61 & 0.54 & 0.33 & 0.35 & 0.31 & 19 & 29 \\
\hline
\end{tabular}




\begin{tabular}{|c|c|c|c|c|c|c|c|c|c|c|c|}
\hline \multicolumn{12}{|c|}{ Table 1: Continued } \\
\hline \multicolumn{12}{|c|}{ Healthcare } \\
\hline 300 & Chiropractors & 97.8 & 61.11 & 0.32 & 0.38 & 0.27 & 0.21 & 0.25 & 0.19 & 19 & 29 \\
\hline 301 & Dentists & 98.8 & 102.84 & 0.20 & 0.23 & 0.18 & 0.15 & 0.17 & 0.13 & 19 & 29 \\
\hline 304 & Optometrists & 99.4 & 80.02 & 0.37 & 0.42 & 0.34 & 0.24 & 0.27 & 0.22 & 19 & 29 \\
\hline 305 & Pharmacists & 97.6 & 68.25 & 0.95 & 0.92 & 0.97 & 0.45 & 0.45 & 0.45 & 19 & 29 \\
\hline 306 & Physicians and Surgeons & 98.8 & 124.13 & 0.38 & 0.44 & 0.34 & 0.25 & 0.28 & 0.23 & 19 & 29 \\
\hline 312 & Podiatrists & 99.4 & 83.11 & 0.21 & 0.27 & 0.17 & 0.14 & 0.16 & 0.12 & 19 & 26 \\
\hline 325 & Veterinarians & 98.8 & 61.10 & 0.73 & 0.89 & 0.63 & 0.38 & 0.44 & 0.34 & 19 & 29 \\
\hline 354 & Other Healthcare Practioners and Technical & 82.0 & 40.07 & 0.68 & 0.77 & 0.62 & 0.37 & 0.40 & 0.34 & 19 & 29 \\
\hline \multicolumn{12}{|c|}{ Transportation } \\
\hline 903 & Aircraft Pilots and Flight Engineers & 85.1 & 62.42 & 0.05 & 0.06 & 0.04 & 0.04 & 0.05 & 0.04 & 19 & 29 \\
\hline & Sample Means over 56 Occupations & 90.63 & 60.70 & 0.45 & 0.47 & 0.43 & 0.25 & 0.26 & 0.24 & & \\
\hline
\end{tabular}

Moreover, women comprise less than 50 percent of all workers across all states in each occupation identified as male-dominated.

The concentration of women relative to men who were employed in each of the 56 occupations during the 2000 Presidential election year varies both across states and occupations. The variation in female representation across occupations can be gauged by examining the 56 values of the mean state GCQ that represents the average extent of female segregation in each occupation over all states. The variation in female representation across blue states and red states within an occupation can be measured by comparing the occupation's GCQ averaged over only blue states (mean blue state GCQ) and averaged over only red states (mean red state GCQ). For example, the mean state GCQ for civil engineers is 0.12 meaning that the average concentration of women working as civil engineers is 88 percent less than the average concentration of men working in that occupation across all states in Census year 2000. Within blue states, the average concentration of women civil engineers is 87 percent less than the average concentration of men working in that occupation whereas, within red states, the average concentration of women civil engineers is 89 percent less than the average concentration of men working in that occupation.

The mean state GCQs range from a low of 0.05 for aircraft pilots and flight engineers to a high of 1.08 for database administrators. Moreover, the mean state GCQ over all 56 occupations is approximately 0.45 indicating that, on average, across all states, women's participation in high-education, male-dominated occupations is 55 percent lower than men's. The average GCQ across occupations in blue states is about 4 percentage points higher than in red states; women's representation in high-education, high-paying, male-dominated occupations was lower in those states with a Republican majority in the 2000 Presidential election.

Summary measures of the earnings and educational attainment show that the average median earnings in these high-education occupations are substantially higher than the approximately $\$ 30,000$ median earnings of all workers in the U.S. in 2000 . The mean national median earnings of these occupations is $\$ 60,700$. Moreover, summary measures for education show that on average, 91 percent of those employed in the 56 occupations across all states in our study are college graduates.

\section{MODELING DIFFERENCES IN OCCUPATIONAL SEGREGATION}

We base our estimation of the red-state/blue-state difference in the average concentration of women (relative to men) employed in male-dominated, high-education occupations on analysis of the 56 male-dominated, high-education occupations' GCQs in each of the 48 states that employ workers in the occupation. The reduced-form regression explains occupational 
variation in $G C Q_{i}$ within each state by differences in the earnings and education of those employed in the occupation, and explains state variation in $\mathrm{GCQ}_{\mathrm{s}}$ within each occupation by differences in state demographic and economic factors.

Our GCQ regression specification is based on the equilibrium models used by Johnes (2000) and Grossman et al. (2015) that incorporate gender differences in occupational choice. We include control variables that previous studies found to be important in explaining regional differences in occupational segregation. If the gender concentration quotient is the equilibrium outcome of female-to-male rates of employment in occupation $i$ in state $s$, then we would expect the GCQ to vary across states according to states' gender ratios of qualified workers and gender ratios of reservation wages.

We measure occupational earnings as the natural log of median earnings of full-time workers employed in occupation $i$ (logOccEarni) and measure occupational education as the percentage of full-time workers in the occupation $i$ with a college degree (occpctba $i)$. We include the log ratio of female-to-male state median earnings (IFtoMmedearn $)$ as a proxy for the gender pay ratio of alternative employment in the state (or the ratio of reservation wages) and the $\log$ ratios of female to male state percentage of college graduates (lFtoMpctbas $)$ and state percentage of educational attainment greater than a college degree $\left(l F t o M g t b a_{s}\right)$ as proxies for the state gender ratios of qualified workers.

We also include several interacted explanatory variables that allow the effects of the occupational characteristics on the gender concentration quotient to depend on the degree of gender equality in the state. For example, we include the interaction of lFtoMmedearns with $\operatorname{logOccEarn} i$ to measure gender differences in the effect of occupational earnings differentials on

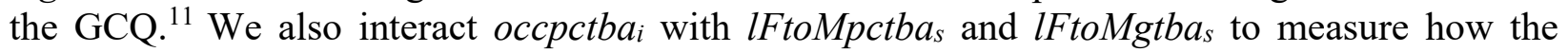
state gender education ratios affect the gender concentration ratio differently in occupations that require specialized skills. That is, we expect that a more intensified skill set is required for employment in an occupation in which 95 percent of its workers have a college degree than are required for employment in an occupation in which only 80 percent of workers are college graduates.

We expect a lower GCQ in male-dominated, high-education occupations in states that are politically conservative and that have more traditional views of women's role in society compared to states that are more supportive of gender equality in the workplace. We model the effects of these expected systematic differences in the political and social environments as differences in the GCQ regression coefficients for red states versus blue states on the explanatory variables: the natural log of the occupation's median earnings, the share of an occupation's workers with a college degree, the natural log of both the states' gender education and earnings ratios, and the natural log percent of the state population that adheres to an evangelical religion

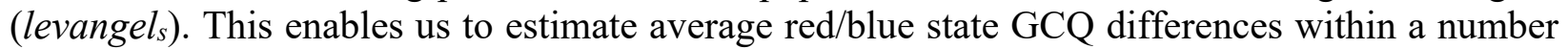
of occupational earnings and education categories and to gauge whether the red/blue state difference depends on the degree of gender earnings and gender education equality in the states.

\footnotetext{
${ }^{11}$ Both Johnes (2000) and Grossman et al. (2015) find that women's employment response to expected occupational earnings differentials is much smaller than men's. Johnes (2000) conjectures that occupational segregation might prevent women from freely responding to wage differentials. The social interaction models of Pan (2015) and Flabbi (2010) predict that worker or employer prejudice causes women's equilibrium wages to fall relative to the zero-prejudice equilibrium thus artificially reducing women's reservation wages.
}

(C) Southern Regional Science Association 2017. 
The GCQ regression model, thus, takes the form

$$
\begin{gathered}
\beta_{2, r(s)} \text { occpctba }_{i}+\beta_{3, r(s)}\left(\text { occpctba }_{i} * \text { lFtoMpctba }_{s}\right)+\beta_{4, r(s)}\left(\text { occpctba }_{i} *\right. \\
\text { lFtoMgtba } \left._{s}\right)+\beta_{5, r(s)} \text { lFtoMpctba }_{s}+\beta_{6, r(s)} \text { lFtoMgtba }_{s}+\beta_{7, r(s)} \log \text { OccEarn }_{i}+ \\
\beta_{8, r(s)} \text { FtoMmedearn }_{s}+\beta_{9, r(s)}\left(\log \text { OccEarn }_{i} * \text { FtoMmedearn }_{s}\right)+ \\
\beta_{10, r(s)} \text { levangel }_{s}+\text { xstate }_{i, s}^{\prime} \delta+\beta_{1, r(s)}+\sum_{h(i)=1}^{11} \gamma_{h(i)} \text { occgroup }_{h(i)}+\varepsilon_{i, s}
\end{gathered}
$$

where $i$ identifies the occupation, $s$ identifies the state, $r(s)$ is the binary red-state/blue-state indicator that takes the value one if state $s$ is a red state. In this way, the regression coefficients take on different values for red states and blue states. The dummy variables occgroup ori $_{i}$ through occgroup $_{11(i)}$ refer to the eleven broad occupational categories (management, business and financial, computer and math, architects and engineers, life, physical and social scientists, community and social services, legal education, arts, healthcare, and transportation). If occupation $i$ is in occupational category $h$, then $\operatorname{occgroup}_{h(i)}=1$; otherwise, $\operatorname{occgroup}_{h(i)}=0$. The occupational group fixed effect, $\gamma_{h(i)} \operatorname{occgroup}_{h(i)}$, represents the influence of unobservable factors that are specific to the occupational category and that are common across states.

The vector, $x_{\text {state }}$, includes other state demographic and economic features that previous research has used to predict broadly defined measures of female segregation in the labor market or to predict Republican voting outcomes by region (Olfert and Moebis, 2006; McVeigh and Sobolewski, 2007). We restrict the regression coefficients on the state control variables to be the same across occupations and states. The demographic characteristics include the natural $\log$ of the state population's median age (lmedages), the share of the state population born outside the U.S. (lforeigns), a measure of mobility of the population (lmobiles), and state's population density (ldensitys). ${ }^{12}$

We control for state differences in overall labor market activity by including the logs of the state employment rate (lemprates) and the ratio of female to male state employment rates $($ lFtoMemppc $)$. To account for the size of industry, we include the logs of the percentage of firms in the state with more than 500 employees $\left(l p c t 500_{s}\right)$, and the percentage of workers in management and professional occupations (lptmanages and lptprof $_{s}$, respectively). We also include the logged values of the percentage of workers in the state who are employed in the specific male-dominated, high-education occupation (lpoccstates) as a measure of the occupation's relative importance in the state labor market. ${ }^{13}$

Grossmann et al. (2015) find that a more religiously and politically conservative background increases the probability of choosing to major in a STEM field for men but has no effect on women's choice of major. Therefore, we might expect a higher share of men with STEM majors in more politically and religiously conservative red states than in blue states. Because the 2000 U.S. census does not contain information on the undergraduate major of the college-educated population and because we can only control for differences in female and male educational attainment at an aggregate state level, we estimate separate regression models

\footnotetext{
12 Olfert and Moebis (2006) found that those regions in Canada that were the most rural displayed the highest amount of overall occupational segregation. We include the (log of the) state's population density as a continuously decreasing measure of the state's rurality.

${ }^{13}$ If male worker and/or employer prejudice against female workers is greater in occupations of more economic importance in the state, we might expect the GCQ to be lower in occupations that employ more workers in the state.
}

(C) Southern Regional Science Association 2017. 
relating the GCQ to occupation and state characteristics for non-STEM and STEM occupations. $^{14}$

\section{ESTIMATION RESULTS}

Results from estimating Equation 1 for STEM and non-STEM occupations are presented in Table 2. The top panel contains the estimated coefficients that differ across red states and blue states. We use these estimates to calculate the red state marginal effects and the blue state marginal effects that are presented in Table 3. These coefficients also determine the average $\mathrm{red} / \mathrm{blue}$ state differences that are presented in Table 4.

The bottom of Table 2 presents the estimated coefficients on the state control variables in the non-STEM and STEM occupations regressions that do not vary between red and blue states. We find that the positive and statistically significant estimated coefficient of 0.04 on ldensity is consistent with Olfert's finding that overall gender occupational segregation is greater within more-rural provinces in Canada. The point estimate indicates that the average concentration of females relative to males employed in each of the (STEM and non-STEM) occupations is approximately 0.032 higher in states that are one standard deviation more densely populated than other states. The relative importance of a more densely populated state for gender equality in employment varies across occupations. The 0.032 higher GCQ associated with a one standard deviation increase in a state's population density corresponds to a 21 percent increase in the relative concentration of female employment in architecture and engineering occupations, and a 7 percent increase in those occupations with an average-valued GCQ.

The relative importance of the occupation (in terms of the proportion of total state employment) as measured by the estimated coefficient on lpoccstate, has a statistically significant and negative effect on female representation in STEM occupations, but no discernable effect on female representation within non-STEM occupations. States with a higher share of mobile residents, as measured by the coefficient on lmobile, have a higher relative female representation in non-STEM occupations than states with less mobile residents. This association is absent within STEM occupations. The estimated coefficient on (the natural log of) the percent of firms with more than 500 employees (lpct500) is positive and statistically significant for STEM occupations and is small and statistically insignificant for non-STEM occupations. The coefficient estimate of 0.09 indicates that a one standard deviation increase in a state's percentage of large firms is associated with an approximately 6.6 percentage point higher average GCQ in STEM occupations. Finally, female representation in both non-STEM and STEM occupations is estimated to be higher, on average, in right-to-work states although the estimated coefficients (RtoWork) are only marginally statistically significant in both regressions.

The coefficients in the top panel of Table 2 appear to differ substantially in the STEM and non-STEM occupations regressions and the coefficients for red states differ from those for blue states within each of the regressions. Although it is difficult to interpret the estimated values of the coefficients on the interacted variables, it is straightforward to evaluate the estimated coefficients on the percent of state residents that practice evangelical religions (levangel). In both STEM and non-STEM occupations, the results show that the GCQ is lower in states with a higher proportion of evangelicals. According to the point estimates, the GCQ in non-STEM occupations is approximately .048 lower ( 9 percent of its mean value) in red states where the

\footnotetext{
${ }^{14}$ Descriptive statistics of the occupation and state characteristics that we include in the regression model are presented in Table A1 in the Appendix.
}

(C) Southern Regional Science Association 2017. 
Table 2: Estimation Results for STEM and non-STEM occupations in Red and Blue States

\begin{tabular}{|c|c|c|c|c|c|c|c|c|}
\hline \multirow[b]{3}{*}{ Explanatory Variable } & \multicolumn{4}{|c|}{ GCQ in non-STEM Occupations } & \multicolumn{4}{|c|}{ GCQ in STEM Occupations } \\
\hline & \multicolumn{2}{|c|}{ Red States } & \multicolumn{2}{|c|}{ Blue States } & \multicolumn{2}{|c|}{ Red States } & \multicolumn{2}{|c|}{ Blue States } \\
\hline & coef est & std error & coef est & std error & coef est & std error & coef est & std error \\
\hline constant & 0.514 & 1.564 & 0.372 & 1.318 & $3.993 * *$ & 1.785 & -1.392 & 4.725 \\
\hline occpctba & $.014 * * *$ & 0.003 & $-0.008 * * *$ & 0.003 & -0.003 & 0.009 & 0.044 & 0.011 \\
\hline occpctba*1FtoM_pctba & -0.019 & 0.020 & $-.065 * *$ & 0.013 & $-0.295 * *$ & 0.147 & $0.146^{* *}$ & 0.064 \\
\hline occpctba*1FtoMgtba & $.024 * * *$ & 0.009 & $.015^{*}$ & 0.013 & $0.084 *$ & 0.049 & 0.017 & 0.031 \\
\hline 1FtoMpctba & 2.527 & 1.830 & $6.268 * * *$ & 1.147 & $28.441 * *$ & 13.454 & $-11.686^{* *}$ & 5.665 \\
\hline 1FtoMgtba & $-2.371 * * *$ & 0.864 & -1.267 & 1.146 & $-8.365^{*}$ & 4.521 & 0.017 & 0.031 \\
\hline logOccEarn & $-.471 * * *$ & 0.109 & $-.123 * * *$ & 0.133 & $-0.884 * * *$ & 0.307 & -0.401 & 0.943 \\
\hline logOccEarn*1FtoMmedearn & $.615 * *$ & 0.295 & $1.038^{* *}$ & 0.412 & 0.002 & 0.992 & 1.441 & 2.875 \\
\hline 1FtoMmedearn & -3.094 & 1.230 & -3.828 & 1.623 & -0.344 & 4.047 & -4.868 & 11.656 \\
\hline levangel & $-.250 * * *$ & 0.070 & $-0.071 * *$ & 0.027 & -0.106 & 0.089 & $-0.155 * * *$ & 0.041 \\
\hline State Control Variables & coef est & std error & t-stat & p-value & coef est & std error & t-stat & p-value \\
\hline lpoccstate & 0.007 & 0.009 & 0.79 & 0.436 & -0.056 & 0.019 & -3 & 0.004 \\
\hline lmedage & -0.135 & 0.208 & -0.65 & 0.521 & 0.093 & 0.208 & 0.45 & 0.658 \\
\hline lforeign & -0.033 & 0.027 & -1.21 & 0.233 & 0.013 & 0.048 & 0.27 & 0.786 \\
\hline ldensity & 0.038 & 0.013 & 2.98 & 0.005 & 0.038 & 0.015 & 2.51 & 0.016 \\
\hline lmobile & 0.491 & 0.157 & 3.13 & 0.003 & -0.024 & 0.255 & -0.09 & 0.926 \\
\hline lemprate & -0.146 & 0.173 & -0.84 & 0.404 & -0.263 & 0.305 & -0.86 & 0.392 \\
\hline 1FtoMemppc & -0.812 & 0.541 & -1.5 & 0.14 & -0.676 & 0.551 & -1.23 & 0.226 \\
\hline lpct500 & 0.013 & 0.022 & 0.59 & 0.561 & 0.088 & 0.034 & 2.55 & 0.014 \\
\hline lptmanage & 0.260 & 0.161 & 1.61 & 0.113 & 0.161 & 0.190 & 0.85 & 0.401 \\
\hline lptprof & -0.165 & 0.138 & -1.2 & 0.236 & -0.177 & 0.156 & -1.14 & 0.26 \\
\hline RtoWork & 0.025 & 0.016 & 1.63 & 0.11 & 0.041 & 0.024 & 1.67 & 0.101 \\
\hline R-squared & & 0.3813 & & & & 0.2239 & & \\
\hline Number of observations & & 1097 & & & & 1533 & & \\
\hline
\end{tabular}

Regressions include occupation category dummy variables and the reported standard errors are clustered by states. The explanatory variables in the upper panel are the percent of workers in the occupation that have a bachelor's degree, and the logarithms of the state ratios of \%females to \%males with a bachelor's degree, state ratio of \%females to \%males with more than a bachelor's degree, median earnings of full-time workers in the occupation, state ratio of median earnings of females to median earnings of males, and the \% state population that adheres to evangelical religions. The state control variables are the logarithms of the state $\%$ employed in the occupation, state median age, $\%$ state population born outside the US, state population density (pop/sq miles), $\%$ state residents $>5$ yrs living in a different location than 5 yrs ago, state employment rate (population $17 \mathrm{yrs} \&$ older), ratio of $\%$ females employed to $\%$ males employed, state $\%$ of firms with $>500$ employees, state $\%$ employed in management occupations, and state \% employed in professional occupations, and a state Right-to-Work dummy variable.

proportion of evangelicals is 21 percent higher than in other red states. (The standard deviation of the proportion of evangelicals is 21 percent of its mean value in red states.) In STEM occupations, the estimated coefficient indicates a 5 percent fall in the GCQ associated with the same increase in the proportion of evangelicals although the estimate is statistically insignificant. In blue states, a one standard deviation increase in the proportion of evangelicals from its mean is associated with a 3 percent decline in the GCQ relative to its mean in non-STEM occupations and a 9 percent relative decrease in STEM occupations.

We complete our discussion of the results by examining the partial effects presented in Table 3. To interpret the marginal effects of the percent of the occupation's workers with a bachelor's degree (occpctba), state ratios of female-to-male educational attainment (lFtoMpctba, lFtoMgtba), state ratios of female-to-male earnings (lFtoMmedearn), and the log of occupational earnings (logOccEarn), one must combine several of the individual coefficient estimates from Table 2. These calculated marginal effects are presented in Table 3. 


\section{Table 3: Partial Effects of Occupational Education, logEarnings, logs of Female-to-Male State Earnings and of State Education Ratios: Estimates from GCQ Regression Model (1) using Census 2000 High-Education, Male Dominated Occupations}

\begin{tabular}{|c|c|c|c|c|c|c|c|c|c|c|c|c|}
\hline \multirow[b]{3}{*}{ Variable (x) } & \multicolumn{12}{|c|}{ non-STEM Occupations } \\
\hline & \multicolumn{3}{|c|}{ Average dGCQ/dx } & \multicolumn{3}{|c|}{$\begin{array}{l}\mathrm{dGCQ} / \mathrm{dx} \text { at } 25 \mathrm{th} \\
\text { percentiles }\end{array}$} & \multicolumn{3}{|c|}{ dGCQ/dx at medians } & \multicolumn{3}{|c|}{ dGCQ/dx at 75 th percentiles } \\
\hline & red & blue & difference & red & blue & difference & red & blue & difference & red & blue & difference \\
\hline occpctba & -0.009 & -0.004 & -0.005 & -0.009 & -0.003 & -0.006 & -0.009 & -0.004 & -0.005 & -0.005 & -0.007 & -0.003 \\
\hline std error & 0.002 & 0.001 & 0.001 & 0.002 & 0.002 & 0.002 & 0.002 & 0.002 & 0.002 & 0.001 & 0.002 & 0.001 \\
\hline p-value & 0.000 & 0.006 & 0.002 & 0.000 & 0.109 & 0.001 & 0.000 & 0.009 & 0.002 & 0.000 & 0.000 & 0.048 \\
\hline loccearn & -0.371 & -0.457 & 0.086 & -0.389 & -0.488 & 0.099 & -0.369 & -0.453 & 0.085 & -0.351 & -0.423 & 0.072 \\
\hline std error & 0.023 & 0.027 & 0.023 & 0.023 & 0.030 & 0.028 & 0.023 & 0.027 & 0.024 & 0.026 & 0.029 & 0.029 \\
\hline$p$-value & 0.000 & 0.000 & 0.000 & 0.000 & 0.000 & 0.000 & 0.000 & 0.000 & 0.000 & 0.000 & 0.000 & 0.013 \\
\hline IFtoMpctba & 0.805 & 0.276 & 0.529 & 0.901 & 0.653 & 0.249 & 0.804 & 0.272 & 0.533 & 0.679 & -0.221 & 0.900 \\
\hline std error & 0.465 & 0.339 & 0.450 & 0.474 & 0.324 & 0.450 & 0.465 & 0.339 & 0.451 & 0.493 & 0.381 & 0.510 \\
\hline p-value & 0.090 & 0.419 & 0.240 & 0.063 & 0.050 & 0.580 & 0.090 & 0.428 & 0.237 & 0.175 & 0.565 & 0.078 \\
\hline IFtoMgtba & -0.172 & 0.169 & -0.340 & -0.307 & 0.078 & -0.385 & -0.170 & 0.170 & -0.340 & 0.007 & 0.288 & -0.281 \\
\hline std error & 0.183 & 0.194 & 0.284 & 0.196 & 0.198 & 0.299 & 0.183 & 0.194 & 0.284 & 0.185 & 0.228 & 0.305 \\
\hline$p$-value & 0.352 & 0.390 & 0.230 & 0.125 & 0.694 & 0.197 & 0.356 & 0.387 & 0.231 & 0.970 & 0.213 & 0.357 \\
\hline IFtoMearn & -0.591 & 0.430 & -1.021 & -0.700 & 0.246 & -0.946 & -0.593 & 0.427 & -1.020 & -0.419 & 0.722 & -1.140 \\
\hline std error & 0.269 & 0.218 & 0.298 & 0.273 & 0.203 & 0.295 & 0.269 & 0.218 & 0.298 & 0.282 & 0.283 & 0.352 \\
\hline \multirow[t]{3}{*}{ p-value } & 0.033 & 0.055 & 0.001 & 0.014 & 0.232 & 0.001 & 0.032 & 0.056 & 0.001 & 0.144 & 0.014 & 0.001 \\
\hline & \multicolumn{12}{|c|}{ STEM Occupations } \\
\hline & \multicolumn{3}{|c|}{ Average dGCQ/dx } & \multicolumn{3}{|c|}{$\begin{array}{l}\mathrm{dGCQ} / \mathrm{dx} \text { at } 25 \text { th } \\
\text { percentiles }\end{array}$} & \multicolumn{3}{|c|}{ dGCQ/dx at medians } & \multicolumn{3}{|c|}{$\mathrm{dGCQ} / \mathrm{dx}$ at 75 th percentiles } \\
\hline Variable (x) & red & blue & difference & red & blue & difference & red & blue & difference & red & blue & difference \\
\hline occpctba & 0.012 & 0.022 & -0.010 & 0.016 & 0.017 & -0.001 & 0.013 & 0.022 & -0.009 & 0.011 & 0.027 & -0.016 \\
\hline std error & 0.004 & 0.003 & 0.004 & 0.003 & 0.003 & 0.004 & 0.004 & 0.003 & 0.004 & 0.004 & 0.005 & 0.004 \\
\hline$p$-value & 0.002 & 0.000 & 0.008 & 0.000 & 0.000 & 0.821 & 0.001 & 0.000 & 0.013 & 0.009 & 0.000 & 0.000 \\
\hline loccearn & -0.885 & -0.863 & -0.021 & -0.855 & -0.907 & 0.023 & -0.885 & -0.859 & -0.026 & -0.885 & -0.817 & -0.068 \\
\hline std error & 0.137 & 0.094 & 0.130 & 0.148 & 0.117 & 0.108 & 0.136 & 0.096 & 0.136 & 0.131 & 0.143 & 0.203 \\
\hline p-value & 0.000 & 0.000 & 0.869 & 0.000 & 0.000 & 0.834 & 0.000 & 0.000 & 0.847 & 0.000 & 0.000 & 0.738 \\
\hline IFtoMpctba & 1.851 & 1.480 & 0.371 & 3.284 & 0.770 & 2.514 & 1.367 & 1.719 & -0.353 & 0.364 & 2.216 & -1.852 \\
\hline std error & 0.498 & 0.463 & 0.508 & 1.045 & 0.459 & 1.068 & 0.438 & 0.509 & 0.478 & 0.666 & 0.652 & 0.773 \\
\hline$p$-value & 0.001 & 0.003 & 0.465 & 0.003 & 0.100 & 0.019 & 0.003 & 0.002 & 0.460 & 0.587 & 0.001 & 0.017 \\
\hline IFtoMgtba & -0.746 & -0.218 & -0.528 & -1.157 & -0.299 & -0.857 & -0.608 & -0.191 & -0.417 & -0.320 & -0.134 & -0.187 \\
\hline std error & 0.191 & 0.284 & 0.334 & 0.366 & 0.255 & 0.461 & 0.172 & 0.310 & 0.337 & 0.237 & 0.380 & 0.419 \\
\hline$p$-value & 0.000 & 0.446 & 0.114 & 0.003 & 0.247 & 0.063 & 0.001 & 0.541 & 0.216 & 0.184 & 0.727 & 0.656 \\
\hline IFtoMearn & -0.336 & 0.969 & -1.305 & -0.337 & 0.792 & -1.129 & -0.336 & 0.951 & -1.287 & -0.336 & 1.196 & -1.532 \\
\hline std error & 0.348 & 0.302 & 0.341 & 0.373 & 0.470 & 0.520 & 0.349 & 0.305 & 0.345 & 0.376 & 0.537 & 0.569 \\
\hline p-value & 0.339 & 0.002 & 0.000 & 0.372 & 0.099 & 0.030 & 0.340 & 0.003 & 0.000 & 0.377 & 0.031 & 0.007 \\
\hline
\end{tabular}


The partial effect of occupational education (occpctba) on the GCQ holds constant the occupation's earnings. Likewise, the partial effect of occupational earnings (logOccEarn) on the GCQ holds constant the occupation's educational attainment. The results indicate that, in nonSTEM occupations with the same median earnings, the concentration of women relative to men is lower in both red and blue states in occupations with more highly educated workers. In STEM occupations, however, the concentration of women relative to men is higher in both red and blue states in occupations with more highly educated workers. According to the point estimates, as occpctba increases by 10 percentage points (for example, increasing from 85 to 95 percent), in non-STEM occupations, the average GCQ decrease over all red states is 0.09 and, over all blue states, is 0.04 . The same 10 percentage point increase in workers' educational attainment in STEM occupations is associated with an average GCQ increase of 0.04 over red states and 0.20 in blue states. The estimated partial effect of education (occpctba) on the gender concentration ratio in STEM occupations is greatest in both red states and blue states when the state ratios of female to male educational attainment are at the $75^{\text {th }}$ percentiles.

In occupations that employ the same percentages of workers with a college degree, our results indicate that the concentration of women relative to men decreases as the occupation's median earnings increases. The pattern of decreased female representation in higher-paying occupations with the same educational characteristics exists in both non-STEM and STEM occupations within both red and blue states. This appears to be unrelated to the degree of gender earnings equality in the state as evidenced by the constant values of the partial effects of the $\log$ of occupational earnings. The estimated average partial effects of increased occupational earnings are approximately twice the magnitude in STEM occupations than in non-STEM occupations but are the same magnitude for blue and red states for non-STEM and STEM occupations. According to the average partial effect estimates, as median occupational earnings increases by 10 percent, the average GCQ in non-STEM occupations decreases by approximately 0.04 in red states and 0.05 in blue states and, in STEM occupations the average GCQ falls by approximately 0.09 in both red and blue states.

The estimated partial effects of the state gender earnings and education ratios show how the state's degree of gender equity in earnings and educational attainment affects the state's gender concentration ratio in occupations with the same educational and earnings characteristics. Our point estimates of the partial effects of lFtoMpctba suggest that both red and blue states with a higher gender (female-to-male) ratio of college graduates have higher gender concentration ratios in both non-STEM and STEM occupations. In non-STEM occupations, although the estimated effect is positive in blue states, it is statistically significant only in occupations with percent of college graduates at the $25^{\text {th }}$ percentile. In STEM occupations, the increase in the GCQ as lFtoMpctba increases is positive and statistically significant in both red and blue states but the magnitude of the effect is smaller in occupations with more highly educated workers in red states and is larger in occupations with more highly educated workers in blue states.

The partial effect of lFtoMgtba measures the change in the GCQ from an increase in the state gender ratio of educational attainment greater than college, holding constant the state ratio of female-to-male shares of workers with a bachelor's degree. In non-STEM occupations, the red (blue) state point estimates are negative (positive) and statistically insignificant but exhibit a pattern of decreasing magnitude in occupations employing a higher share of college graduates. In STEM occupations, the estimated partial effects show relatively large and statistically significant declines in the red state GCQ associated with increases in the state gender ratio of educational 
attainment greater than college. The estimated magnitude of the partial effect in red states is smaller in STEM occupations with higher values of occpctba. Although the GCQ in blue states is also predicted to fall as lFtoMgtba increases, the estimates are smaller than those for red states and the estimates are statistically insignificant.

One of the most striking red-state/blue-state differences is in their partial effects of the state gender earnings ratio on the gender concentration quotient. The estimation results from both the non-STEM and STEM regressions show that the GCQ in red states decreases as the state gender earnings ratio (lFtoMmedearn) increases, whereas the GCQ in blue states increases as the state's gender earnings ratio (lFtoMmedearn) increases. In STEM occupations, the magnitudes of the GCQ's response to increased gender earnings equality in the state appear unrelated to the occupation's median earnings. But, in non-STEM occupations, the magnitudes of the partial effects of increased state gender earnings equality on the GCQ are greater in occupations with higher median earnings. That is, in blue states employment equality is greater in states with greater gender pay equality. Still, this effect is greater in non-STEM occupations with higher earnings.

Tables 4 and 5 present the predicted differences between the mean GCQ in red states and the mean GCQ in blue states for occupations in eight different educational and earnings categories for non-STEM and for STEM occupations. The occupations are divided into four education groups - those with 80 to 85,85 to 90,90 to 95 , and 95 to 100 percent of their employees having a bachelor's degree. The occupations are divided into two earnings groups median earnings of $\$ 55,000$ or less and greater than $\$ 55,000$. The predicted red-state/blue-state GCQ differences are evaluated at the median earnings (logOccEarn $i)$ and median education (occpctbai) of those occupations in each of the eight occupational education/earnings categories. ${ }^{15}$ In the first two rows of the tables, the estimates pertain to states with median gender earnings and education ratios; in the second two rows, the estimates pertain to states with gender earnings and education ratios at the $75^{\text {th }}$ percentiles of all states. ${ }^{16}$ Comparing the estimated GCQ red-blue state differences within the same occupational category shows us whether the estimated red-blue state gender employment gap (GCQ difference) increases or decreases with the state gender gaps in earnings and educational attainment.

The estimated red-blue state differences in the gender concentration quotient in the nonSTEM occupations are presented in Table 4. The results indicate that women's representation is closer to that of their male counterparts' (the GCQ is higher) in blue states than in red states within each occupational earnings and education category. The estimates of expected GCQ differences in the first two rows of Table 4 are between red and blue states with gender earnings and education ratios at the median values of all states, and those in the bottom two rows are between red and blue states with gender earnings and education ratios at the $75^{\text {th }}$ percentiles where the state gender gaps in both earnings and educational attainment are smaller. The estimated difference in the GCQ in each occupational group is larger between red and blue states

\footnotetext{
15 Table A2 in the Appendix contains the median values of occpctba, occearn, and the GCQ for each occupation category for both STEM and non-STEM occupations.

16 The medians and $75^{\text {th }}$ percentiles of the following female-to-male ratios of the 48 contiguous US in 2000 are: female to male state median earnings: $0.73,0.75$; ratio of percent females with a college degree to percent males with a college degree: 0.89 , 0.91; ratio of percent females with a masters, professional degree, or Ph.D. to percent male with a masters, professional degree, or Ph.D.: 0.78, 0.84
}

(C) Southern Regional Science Association 2017. 
Table 4: Predicted Mean Difference between Red States' and Blue States' Concentration of Female to Male Employment in High-Education, Male-dominated, non-STEM Occupations using US Census 2000 Data

\begin{tabular}{|c|c|c|c|c|c|c|c|c|c|}
\hline \multicolumn{10}{|c|}{$\mathrm{E}\left(\mathrm{GCQ}\left(\right.\right.$ occ,state)|red state, $X_{0}($ occ, state $\left.)\right)-\mathrm{E}\left(\mathrm{GCQ}(\mathrm{occ}, \mathrm{state}) \mid \mathrm{blue}\right.$ state, $\mathrm{X}_{0}($ occ, state $\left.)\right)$} \\
\hline \multirow{2}{*}{$\begin{array}{l}\text { Ratios of } \\
\text { Female to } \\
\text { Male } \\
\text { Earnings and } \\
\text { Educational } \\
\text { Attainment in } \\
\text { State }\end{array}$} & \multirow{2}{*}{$\begin{array}{c}\text { Median } \\
\text { Earnings } \\
(\$ 1,000) \text { in } \\
\text { Occupation }\end{array}$} & \multicolumn{8}{|c|}{ Percent U.S. Workers in Occupation with College Degree } \\
\hline & & estimate & $\begin{array}{l}\text { std. } \\
\text { error }\end{array}$ & estimate & $\begin{array}{l}\text { std. } \\
\text { error }\end{array}$ & estimate & $\begin{array}{l}\text { std. } \\
\text { error }\end{array}$ & estimate & std. error \\
\hline \multirow{2}{*}{ at medians } & occearn $<=55$ & $-0.107 * * *$ & 0.033 & $-0.115^{* * *}$ & 0.0292 & $-0.135 * * *$ & 0.0288 & $-0.153 * * *$ & 0.0305 \\
\hline & occearn $>55$ & $-0.054^{*}$ & 0.029 & $-0.101 * * *$ & 0.0271 & $-0.098 * * *$ & 0.0267 & $-0.126 * * *$ & 0.0302 \\
\hline \multirow{2}{*}{$\begin{array}{c}\text { at } 75 \text { th } \\
\text { percentiles }\end{array}$} & occearn $<=55$ & $-0.162 * * *$ & 0.0441 & $-0.161 * * *$ & 0.0422 & $-0.169 * * *$ & 0.0424 & $-0.181 * * *$ & 0.044 \\
\hline & occearn $>55$ & $-0.115 * * *$ & 0.0406 & $-0.147 * * *$ & 0.0404 & $-0.140 * * *$ & 0.0403 & $-0.152 * * *$ & 0.0426 \\
\hline
\end{tabular}

The predictions are calculated from the regression estimates provided in Table 2 . The differences are evaluated at the median values of the occupation median earnings and percent workers with a college degree of the occupations falling in each cell. These values are included in appendix Table A2 for both STEM and nonSTEM occupations.

with more gender equality in earnings and educational attainment (bottom two rows) than between red and blue states with less gender earnings and education equality. The results in Table 4 also show a pattern in the size of the red-blue state GCQ difference across the occupational characteristics. Within the non-STEM occupations, the estimated disparity in the female representation in male-dominated, high-education occupations between red states and blue states increases with the educational attainment of the occupation's workforce regardless of the occupation's median earnings. This can be seen by comparing the predicted difference between the mean GCQs in red states and blue states across occupations of varying educational categories in Table 4.

The predicted red-state/blue-state GCQ gap for non-STEM male-dominated, higheducation occupations is greatest in those occupations with between 95 and 100 percent college graduates and with median earnings of no more than $\$ 55,000$. The predicted difference is smallest in those occupations with 80 to 85 percent college graduates and median earnings of more than $\$ 55,000$. In other words, the probability of female employment relative to male employment in the non-STEM, male-dominated, high-education occupations is lower in red states than in blue states and the largest red-state/blue-state difference is in the probability of female relative to male employment in occupations with higher education levels and lower earnings.

The results in Table 5, which focus on STEM occupations, provide no evidence of any difference in the average gender concentration ratio when comparing red states to blue states with gender earnings and education ratios at their median values. However, the estimated difference in the relative concentration of women in the highest education STEM occupations increases dramatically when the state gender ratios are evaluated at the $75^{\text {th }}$ percentiles rather than at their median values. In red states, women's to men's relative employment concentration is between 0.17 and 0.21 lower than in blue states in those STEM occupations with the most highly educated workers. This suggests that, among states with more equal proportions of highly 


\section{Table 5: Predicted Mean Difference between Red States' and Blue States' Concentration of Female to Male Employment in High-Education, Male-dominated, STEM Occupations using US Census 2000 Data}

\begin{tabular}{|c|c|c|c|c|c|c|c|c|c|}
\hline \multicolumn{10}{|c|}{$\mathrm{E}\left(\mathrm{GCQ}(\mathrm{occ}, \mathrm{state}) \mid\right.$ red state, $\mathrm{X}_{0}($ occ, state $\left.)\right)-\mathrm{E}\left(\mathrm{GCQ}(\right.$ occ,state $) \mid$ blue state, $X_{0}($ occ, state $\left.)\right)$} \\
\hline \multirow{3}{*}{$\begin{array}{c}\text { Ratios of } \\
\text { Female to } \\
\text { Male } \\
\text { Earnings and } \\
\text { Educational } \\
\text { Attainment } \\
\text { in State }\end{array}$} & \multirow{3}{*}{$\begin{array}{l}\text { Median } \\
\text { Earnings } \\
(\$ 1,000) \text { in } \\
\text { Occupation }\end{array}$} & \multicolumn{8}{|c|}{ Percent U.S. Workers in Occupation with College Degree } \\
\hline & & \multicolumn{2}{|c|}{$80<=\underset{85}{\text { occpctba }}<=$} & \multicolumn{2}{|c|}{$85<$ occpetba $<=90$} & \multicolumn{2}{|c|}{$90<$ occpetba $<=95$} & \multicolumn{2}{|c|}{ occpctba $>95$} \\
\hline & & $\begin{array}{c}\text { estimat } \\
\mathrm{e}\end{array}$ & $\begin{array}{l}\text { std. } \\
\text { error }\end{array}$ & estimate & $\begin{array}{l}\text { std. } \\
\text { error }\end{array}$ & estimate & $\begin{array}{l}\text { std. } \\
\text { error }\end{array}$ & estimate & std. error \\
\hline \multirow{2}{*}{ at medians } & occearn $<=55$ & 0.0601 & 0.0609 & 0.0119 & 0.0674 & -0.0352 & 0.06 & -0.0662 & 0.0518 \\
\hline & occearn $>55$ & 0.0477 & 0.0572 & 0.0008 & 0.0496 & -0.0464 & 0.0499 & -0.0840 & 0.0553 \\
\hline \multirow{2}{*}{$\begin{array}{l}\text { at } 75 \text { th } \\
\text { percentiles }\end{array}$} & occearn $<=55$ & 0.0645 & 0.0772 & -0.024 & 0.0913 & -0.1154 & 0.0766 & $-0.177 * * *$ & 0.0654 \\
\hline & occearn $>55$ & 0.0386 & 0.0697 & -0.0522 & 0.0648 & $-0.1438^{* *}$ & 0.0729 & $-0.217 * *$ & 0.0859 \\
\hline
\end{tabular}

The predictions are calculated from the regression estimates provided in Table 2 . The differences are evaluated at the median values of the occupation median earnings and percent workers with a college degree of the occupations falling in each cell. These values are included in appendix Table A2 for both STEM and nonSTEM occupations.

educated women and men, women in red states are much less likely to be employed in STEM occupations relative to their male counterparts than women in blue states.

Even after controlling for differences in state demographic, economic, and labor force characteristics, we still find evidence that women in red states fare comparatively worse in maledominated, highly educated non-STEM occupations than women working in the same occupations in blue states. Our results suggest that the predicted gap in women's representation in these occupations reflects value differences between red states and blue states that are associated with the outcome of the 2000 U.S. Presidential election and not the result of differences in state demographics and economic factors. ${ }^{17}$

\section{CONCLUSION}

Despite significant increases in women's overall participation in the labor market in the last third of the twentieth century, occupational segregation remains a dominant feature of employment for women in the U.S. and around the world. As numerous scholars and public policy advocates have pointed out, occupational segregation is a critical barrier to equal opportunity for women.

The policy implications of occupational segregation are many. At the macroeconomic level, occupational segregation creates inefficiency and inflexibility in the labor market. Moreover, occupational segregation is a significant factor contributing to the wage differentials between men and women (Groshen 1991 and Anker 1997). Perhaps most importantly, on a

\footnotetext{
${ }^{17}$ As a check on the robustness of our results with respect to our binary red-blue state indicator of value differences, we ranked blue states and red states by the percent of popular vote for the Republican presidential candidate in the 2000 election and reestimated our GCQ regression using 4 groups of states: blue_low, blue_high, red_low, red_high (where low and high refer to the percentage of Republican votes). The estimated mean GCQ differences between all pairs of red-blue state groups were essentially the same as the red-blue state differences presented in Tables 4 and 5. Moreover, there were no discernible differences between the mean GCQs of red_high and red_low states and the mean GCQs differences between the blue_high and blue_low states were positive for all non-stem occupational categories. These results support our use of a binary red-blue state indicator to proxy for value differences that affect employment outcomes of highly educated women rather than measuring state differences in the percentage of votes for the Republican candidate.
} 
global level occupational segregation limits our ability to compete-a factor that is particularly pernicious when it prevents women from entering science and technological occupations.

To better understand the sources of occupational segregation, we examine differences in occupational segregation by sex in male-dominated, high-education occupations to determine if labor market conditions for women vary according to red-blue state patterns. Controlling for state demographic variables, economic factors, and labor market conditions, our results show that there are indeed differences in labor market outcomes along red-blue state lines, with blue states showing more integrated labor market outcomes in these occupations than red states.

The results of this research show that as the share of state residents who practice evangelical religions rises, the representation of women in high-education, male-dominated STEM and non-STEM occupations declines. Female employment (relative to male employment) in non-STEM occupations is affected more by increased religious conservatism in red states than in blue states and, in STEM occupations, increased religious conservatism in blue states is more important. We find that, given the occupation's educational requirements, the representation of women in both blue and red states falls as the occupation's earnings increases, and this decline is larger in STEM occupations than in non-STEM. In non-STEM occupations with the same earnings, female (relative to male) employment is lower as the educational attainment of the occupation's workers increases; whereas STEM occupations with more highly educated workers have greater female representation.

We also find that the relationship between the degree of state gender equality in earnings and the representation of women varies across non-STEM and STEM occupations and between red and blue states. For example, our results indicate that, in both non-STEM and STEM occupations, the concentration of women (relative to men) in red states decreases as the degree of state gender equality in earnings increases, whereas the relative concentration of females in blue states increases with the degree of state gender equality in earnings. In STEM occupations, the magnitudes of the effects of increased gender earnings equality in the state appear to be unrelated to the occupation's median earnings. But, in non-STEM occupations, the magnitudes of the partial effects of increased state gender earnings equality on women's representation are greater in occupations with higher median earnings.

When we narrow our analysis to determine where this red-blue state gap in women's representation is concentrated by examining eight different educational and earnings categories, we see that women's representation in non-STEM occupations is closer to that of their male counterparts in blue states than red states within each occupational earnings and education category. The red-blue state gap is greatest in those non-STEM occupations with the highest education concentrations and low median earnings and lowest in those non-STEM occupations with the lowest education concentrations and higher median earnings.

When we examine STEM occupations, we see that while there is no difference in the redblue state representation of women using the median measurement of education and earnings by state, and when we evaluate education and earnings at the $75^{\text {th }}$ percentile, we see a dramatic increase in the red-blue state gender occupational concentration gap. That is, in states with more equal proportions of highly educated women and men, women in red states are much less likely to be employed in STEM occupations relative to their male counterparts, than women in blue states.

(C) Southern Regional Science Association 2017. 
These results suggest that there may indeed be important differences in labor market outcomes for women associated with differences in values reflected in the uneven advance of the second demographic transition. If, as demographers have suggested, the second demographic transition is characterized by a convergence of the economic lives of men and women and a values system that places greater emphasis on gender equity, we might indeed see variations in the representation of women in male-dominated, high-education jobs. In fact, we might see variations in a variety of labor market conditions affecting women along red/blue state lines.

The policy implications of this research indicate that programs aimed at increasing the employment of women in male-dominated, high-education occupations would be especially important in red states and highlights the significance of improving women's representation in STEM fields as a mechanism for improving women's labor market opportunities. This might be done through directing resources into programs aimed at increasing women's participation in STEM fields in their educational training both at the secondary levels and at the collegiate level as well as redirecting resources toward training programs for women in such occupations. Efforts by agencies such as the National Science Foundation (NSF) to provide programs such as the ADVANCE Program aimed at increasing the participation and advancement of women in academic science and engineering careers should be enlarged or concentrated where particularly needed. At the same time, more careful attention to affirmative hiring goals in business, finance, engineering, and science occupations would also be helpful — especially in red states.

While there are many reasons why the results presented here should merit attention, globalization challenges our longstanding pre-eminence in scientific knowledge. In order to keep a competitive edge, we should remain mindful of the need to create policies that will facilitate the inclusion of women in male-dominated occupations. Women's participation in STEM fields in higher education, while increasing, remains stubborn in many of these fields. Moreover, women continue to make up only a fifth of the nation's scientific and technical workers.

The results also suggest that differences in values that reflect themselves in voting behavior may also affect a variety of other labor market outcomes for women including wage gaps, job mobility, and representation on boards of directors. While this research is suggestive of labor market differences in one segment of the labor market for women, male-dominated, higheducation occupations, further research along these lines would no doubt add to our understanding of the challenges facing women in the labor market as well as our understanding of the role of values in determining a variety of societal outcomes.

\section{REFERENCES}

Abrahamson, Mark and Lee Sigelman. (1987) "Occupational Sex Segregation in Metropolitan Areas," American Sociological Review, 52, 588-597.

Albelda, Randy P. (1986) “Occupational Segregation by Race and Gender, 1958-81," Industrial and Labor Relations Review, 39, 404-411.

Anker, Richard. (1997) "Theories of Occupational Segregation by Sex: An Overview," International Labor Review, 136, 315-339.

Beller, Andrea H. (1982) "Occupational Segregation by Sex: Determinants and Changes," Journal of Human Resources, 17, 371-392.

(c) Southern Regional Science Association 2017. 
. (1985) "Changes in the Sex Composition of U.S. Occupations, 1960-1985," Journal of Human Resources, 20, 235-250.

Bergmann, Barbara. (1974) "Occupational Segregation, Wages and Profits When Employers Discriminate by Race or Sex,” Eastern Economic Journal, 1, 103-110.

Bertaux, Nancy E. (1991) “The Roots of Today's 'Women's Jobs' and 'Men's Jobs': Using the Index of Dissimilarity to Measure Occupational Segregation by Gender," Explorations in Economic History, 28, 433-459.

Bianchi, Susan M. and Nancy Rytina. (1986) "The Decline in Occupational Sex Segregation During the 1970s: Census and CPS Comparisons," Demography, 23, 79-86.

Blau, Francine D. (1984) "Occupational Segregation and Labor Market Discrimination," in Barbara Reskin, (ed.), Sex Segregation in the Workplace: Trends, Explanations, Remedies. National Academy Press: Washington, DC, pp. 117-143.

Blau, Francine D. and Wallace E. Hendricks. (1979) "Occupational Segregation by Sex: Trends and Prospects," Journal of Human Resources, 14, 197-210.

Blumberg, Rae Lesser. (1979) "A Paradigm for Predicting the Position of Women: Policy Implications and Problems," in Jean Lipman-Blumen and J Bernard (eds.), Sex Roles and Social Policy. Sage: Beverly Hills, CA, pp. 113-142.

Brewer, Mark D. and Jeffrey M. Stonecash. (2007) Split: Class and Cultural Divides in American Politics. CQ Press: Washington DC.

Brunell, Barbara S. (1997) "Some Reflections on the Spatial Dimensions of Occupational Segregation," Feminist Economics, 3, 69-86.

Burt, James E. and Gerald M. Barber. (1996) Elementary Statistics for Geographers. The Guilford Press: New York.

Duncan, Otis Dudley and Beverly Duncan. (1955) "A Methodological Analysis of Segregation Indexes," American Sociological Review, 20, 210-217.

England, Paula. (1982) "The Failure of Human Capital Theory to Explain Occupational Segregation," Journal of Human Resources, 17, 358-370.

Fiorina, Morris P., Samuel J. Abrams, and Jeremy C. Pope. (2006) Culture War? The Myth of a Polarized America. Pearson Longman: New York.

Flabbi, Luca. (2010) "Gender Discrimination Estimation in a Search Model with Matching and Bargaining," International Economic Review, 51, 745-783.

Fullerton Jr., Howard N. (1999) "Labor Force Participation: 75 Years of Change, 1950-98 and 1998-2025," Monthly Labor Review, 122, 3-12.

Goldin, Claudia. (1990) Understanding the Gender Gap: An Economic History of American Women. Oxford University Press: New York.

. (2006) "The Quiet Revolution that Transformed Women's Employment, Education, and Family," American Economic Review, 96, 1-21.

Groshen, Erica L. (1991) "The Structure of the Female/Male Differential: Is it Who You Are, What You Do, or Where You Work?” Journal of Human Resources, 26, 457-472.

(C) Southern Regional Science Association 2017. 
Grossmann, Volker, Aderonke Osikominu, and Marius Osterfeld. (2015) "Are Sociocultural Factors Important for Studying a Science University Major?” CESifo Working Paper No. 5576 \& IZA Discussion Paper No. 9415.

Guiso, Luigi, Paola Sapienza, and Luigi Zingales. (2006) "Does Culture Affect Economic Outcomes?" Journal of Economic Perspectives, 20, 23-48.

Hunter, James Davison. (1991) Culture Wars: The Struggle to Define America. Basic Books: New York.

Jacobs, Jerry A. (1989) "Long-term Trends in Occupational Segregation by Sex," American Journal of Sociology, 95, 160-173.

Jacobsen, Joyce P. (1994) “Trends in Work Force Sex Segregation, 1960-1990," Social Science Quarterly, 75, 204-211.

. (1997) "Trends in Workforce Segregation: 1980 and 1990 Census Figures," Social Science Quarterly, 78, 234-235.

Johnes, Geraint. (2000) "It's Different for Girls: Participation and Occupational Segregation in the USA," The Manchester School, 68, 552-567.

King, Mary C. (1992) “Occupational Segregation by Race and Sex, 1940-88," Monthly Labor Review, 115, 30-37.

Landivar, Liana Christin. (2013) "Disparities in STEM Employment by Sex, Race, and Hispanic Origin," American Community Survey Reports, ACS-24. U.S. Census Bureau: Washington, DC.

Lesthaeghe, Ron. (2010) "The Unfolding Story of the Second Demographic Transition," Population and Development Review, 36, 211-251.

Lesthaeghe, Ron and Lisa Neidert. (2006) “The 'Second Demographic Transition' in the US: Spatial Patterns and Correlates," Populations Studies Center Research Report 06-592, 129.

. (2007) "The Political Significance of the 'Second Demographic Transition' in the US: A Spatial Analysis." Last accessed online in May 2013 at http://sdt.psc.isr.umich.edu/pubs/online/sdt_at_paa2007.pdf.

Lesthaeghe, Ron and Johan Surkyn. (1988) "Cultural Dynamics and Economic Theories of Fertility Change," Population and Development Review, 24, 1-45.

Lorence, Jon. (1992) "Service Sector Growth and Metropolitan Occupational Sex Segregation," Work and Occupations, 19, 128-156.

McVeigh, Rory and Juliana M. Sobolewski. (2007) "Red Counties, Blue Counties, and Occupational Segregation by Sex and Race," American Journal of Sociology, 113, 446506.

Mincer, Jacob and Solomon Polachek. (1974) "Family Investments in Human Capital: Earnings of Women," Journal of Political Economy, 82, 136-155.

Obama, Barack. (2004) Democratic National Convention Keynote Address. Last accessed online in August 2016 at http://www.americanrhetoric.com/speeches/convention2004/barackobama2004dnc.htm.

(C) Southern Regional Science Association 2017. 
Olfert, M. Rose and Dianne M. Moebis. (2006) "The Spatial Economy of Gender-Based Occupational Segregation," Review of Regional Studies, 36, 44-62.

Pan, Jessica Y. (2015) "Gender Segregation in Occupations: The Role of Tipping and Social Interactions," Journal of Labor Economics, 33, 365-408.

Strober, Myra H. (1984) "Toward a General Theory of Occupational Segregation: The Case of Public School Teaching," in Barbara Reskin (ed.), Sex Segregation in the Workplace: Trends, Explanations, Remedies. National Academy Press: Washington, DC, pp. 144 156.

Schelling, Thomas C. (1971) "Dynamic models of segregation," Journal of Mathematical Sociology, 1, 143-186.

U.S. Bureau of the Census. (1999) Statistical Abstract of the United States: 1999 (119 $9^{\text {th }}$ ed). Washington, DC. . (2000) Statistical Abstract of the United States: $2000\left(120^{\text {th }}\right.$ ed.). Washington, DC. 


\section{APPENDIX}

Table A1: Descriptive Statistics of State Controls in Regression

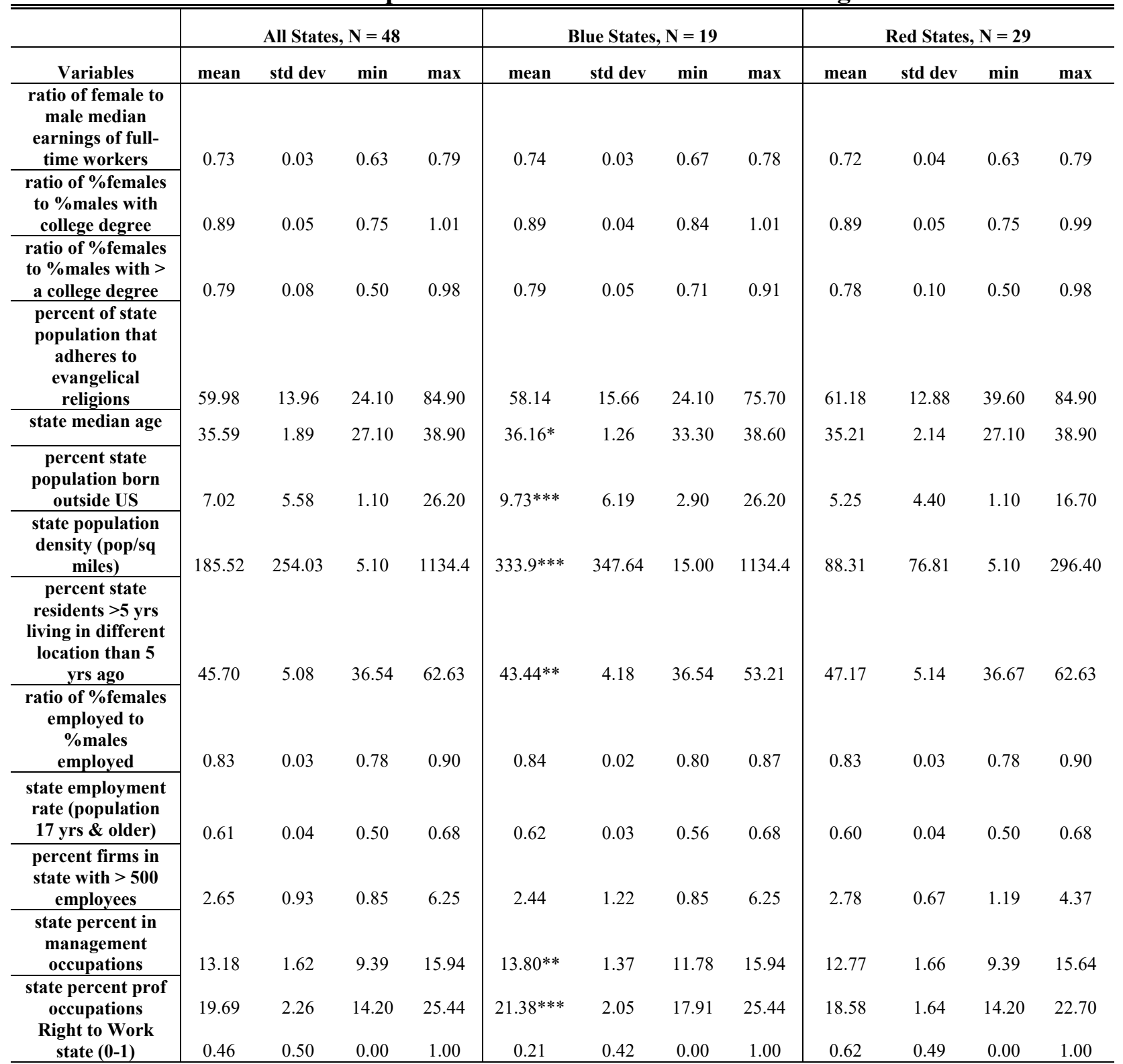


Table A1 Continued

56 High-Education, Male-dominated Occupations (mean \% workers with coll deg = 90.6; mean of occupations' med earnings $=\$ 60,700)$

\begin{tabular}{|c|c|c|c|c|c|c|c|c|c|c|}
\hline \multirow[b]{2}{*}{ Variables } & \multicolumn{5}{|c|}{ Blue States } & \multicolumn{5}{|c|}{ Red States } \\
\hline & $\mathbf{n}$ & mean & std dev & $\min$ & $\max$ & n & mean & std dev & $\min$ & $\max$ \\
\hline $\begin{array}{l}\text { Gender Concentration } \\
\text { Quotient } \\
\text { proportion female }\end{array}$ & 1046 & $0.48 * *$ & 0.48 & 0.00 & 9.54 & 1584 & 0.43 & 0.47 & 0.00 & 12.52 \\
\hline $\begin{array}{l}\text { working in occupation } \\
\text { in state } \\
\text { percentage of state } \\
\text { labor force working in } \\
\text { occupation }\end{array}$ & 1046 & $26.43 * * *$ & 14.54 & 0.00 & 89.74 & 1584 & 24.07 & 14.40 & 0.00 & 91.84 \\
\hline
\end{tabular}

23 Non-STEM Occupations (mean \% workers with coll deg $=90.8$; mean of occupations' med earnings $=$ $\$ 63,300)$

Blue States

Red States

\begin{tabular}{l|ccccc|ccccc}
\hline Variables & $\mathbf{n}$ & mean & std dev & min & max & n & mean & std dev & min & max \\
\hline $\begin{array}{l}\text { Gender Concentration } \\
\text { Quotient } \\
\text { proportion female } \\
\begin{array}{l}\text { working in occupation } \\
\text { in state }\end{array}\end{array}$ & 435 & $0.56^{* * *}$ & 0.32 & 0.00 & 2.04 & 662 & 0.51 & 0.34 & 0.00 & 2.77 \\
$\begin{array}{l}\text { percentage of state } \\
\text { labor force working in } \\
\text { occupation }\end{array}$ & 435 & $0.31^{* * *}$ & 0.13 & 0.00 & 0.64 & 662 & 0.28 & 0.13 & 0.00 & 0.71 \\
& 435 & $0.24 * *$ & 0.30 & 0.00 & 1.22 & 662 & 0.21 & 0.25 & 0.00 & 1.19
\end{tabular}

33 STEM Occupations (mean \% workers with coll deg $=90.5$; mean of occupations' med earnings = $\$ 58,700)$

Blue States

\begin{tabular}{|c|c|c|c|c|c|c|c|c|c|c|}
\hline \multirow[b]{2}{*}{ Variables } & \multicolumn{5}{|c|}{ 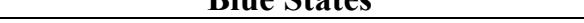 } & \multicolumn{5}{|c|}{ 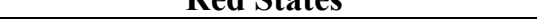 } \\
\hline & n & mean & std dev & $\min$ & $\max$ & n & mean & std dev & $\min$ & $\max$ \\
\hline $\begin{array}{l}\text { Gender Concentration } \\
\text { Quotient } \\
\text { proportion female }\end{array}$ & 611 & 0.41 & 0.56 & 0.00 & 9.54 & 922 & 0.38 & 0.54 & 0.00 & 12.52 \\
\hline $\begin{array}{l}\text { in state } \\
\text { percentage of state } \\
\text { labor force working in } \\
\text { occupation }\end{array}$ & 611 & $0.13 * * *$ & 0.15 & 0.00 & 0.90 & 922 & 0.21 & 0.15 & 0.00 & 0.92 \\
\hline
\end{tabular}

$*, * *, * * *$ indicates that a test of the null hypothesis that the mean of the variable in blue states equals the mean of the variable in red states is rejected at the $10 \%, 5 \%$, or $1 \%$ significance level. The test statistics are constructed using state clustered standard errors that allow for arbitrary heteroskedasticity and correlation within states. 
Table A2: Median Values of Percentage of Workers with a College Degree, Median Earnings (\$1,000), and Gender Concentration Quotient of 56 Occupations in each Earnings and Education Category

\begin{tabular}{clcccc}
\hline $\begin{array}{c}\text { Median Earnings in } \\
\text { Occupation }\end{array}$ & & $\begin{array}{c}\text { Percent Workers in non-STEM Occupation with College Degree } \\
\mathbf{[ 8 0 , 8 5}\end{array}$ & $\mathbf{( 8 5 , 9 0 ]}$ & $\mathbf{( 9 0 , 9 5 ]}$ & $\mathbf{( 9 5 , 1 0 0 ]}$ \\
\hline & occpctba & 81 & 86 & 93 & 95 \\
& occearn & 36.5 & 44.0 & 51.0 & 46.5 \\
Earnings $<=\$ \mathbf{5 5 , 0 0 0}$ & CQ & 0.61 & 0.49 & 0.35 & 0.96 \\
\hline \multirow{3}{*}{ Earnings $>\mathbf{\$ 5 5 , 0 0 0}$} & occpctba & 82 & 88 & 91 & 99 \\
& occearn & 72 & 58 & 71 & 80 \\
& CQ & 0.48 & 0.53 & 0.58 & 0.38 \\
\hline
\end{tabular}

\begin{tabular}{clcccc}
\hline $\begin{array}{c}\text { Median Earnings in } \\
\text { Occupation }\end{array}$ & & $\begin{array}{c}\text { Percent Workers in STEM Occupation with College Degree } \\
\mathbf{[ 8 0 , 8 5}\end{array}$ & $\mathbf{( 8 5 , 9 0 ]}$ & $\mathbf{( 9 0 , 9 5 ]}$ & $\mathbf{( 9 5 , \mathbf { 1 0 0 ] }}$ \\
\hline \multirow{3}{*}{ Earnings $<=\$ \mathbf{5 5 , 0 0 0}$} & occpctba & 82 & 88 & 93 & 96 \\
& occearn & 53 & 41.5 & 44 & 50.5 \\
& CQ & 0.55 & 0.22 & 0.21 & 0.58 \\
\hline \multirow{3}{*}{ Earnings $>\mathbf{\$ 5 5 , 0 0 0}$} & occpctba & 83 & 88 & 93 & 97 \\
& occearn & 60 & 63 & 67 & 70 \\
& CQ & 0.25 & 0.1 & 0.12 & 0.41 \\
\hline \hline
\end{tabular}

(C) Southern Regional Science Association 2017. 